\title{
CAVITATIONAL IRON MICROPARTICLES GENERATION BY PLASMA PROCEDURES FOR MEDICAL APPLICATIONS
}

\author{
Ioan Bica $^{1}$, Madalin Bunoiu ${ }^{1}$, Liviu Chirigiu ${ }^{2}$, Marius Spunei ${ }^{1}$, Iulius Juganaru ${ }^{1}$ \\ ${ }^{1}$ West University of Timisoara, Faculty of Physics, Timisoara, Romania; \\ ${ }^{2}$ Faculty of Pharmacy, University of Medicine and Pharmacy, Craiova, Romania.
}

\section{Article Info \\ Received: 28 December 2011 \\ Accepted: 19 January 2012}

Keywords: Iron microparticles, Microspheres, Pores, Octopusshaped microparticles, Plasma, Microtubes.

\begin{abstract}
The paper presents the experimental installation for the production, in argon plasma, of cavitational iron microparticles (pore microspheres, microtubes and octopus-shaped microparticles). Experimental results are presented and discussed and it is shown that absorbant particles with a minimum iron content are obtained by the plasma procedures
\end{abstract}

\section{Introduction}

Diagnosing and therapy of a number of diseases can be also achieved by the use of ferri- ferromagnetic microparticles. Refs.[1-5] show the advances as well as the limits to magnetic microparticles applicability in medicine. Relatively recent research has revealed that iron microparticles having ad/absorbant properties are of interest for the magnetically controlled transport of anticancer drugs in tumor [6], magnetic hemosorption [7] etc.

Absorbant iron microparticles are of the Ferro-Carbon-4 type [6-8]. They are obtained by the oxidoreduction reaction of iron oxides in the presence of carbon, followed by the formation of an iron nucleus on which carbon is deposited as nanotubes [6]. The quantity of iron in the nucleus of the adsorbant microparticle is an essential parameter in the control of the toxicity of the anticancer terapy with adsorbant iron microparticles $[7,8]$.

Transport of substances in general and that of drugs in particular can also be achieved by means of cavitational microparticles, namely: pore microspheres $[9,10]$, microtubes $[11]$ and octopus-shaped microparticles [12]. In what follows, we set ourselves to describe the procedure for obtaining cavitational microparticles in plasma and to show that by the plasma procedure the quantity of iron can be controlled. 


\section{Experimental installation}

The overall configuration of the installation for the production of cavitational microparticles by plasma procedures is the one shown in Fig.1.a. The installation includes the plasma generator $\mathrm{A}$, the current source $\mathrm{B}$, the material advance system $\mathrm{C}$, the material fixingpositioning system $P$, and the plasmagen gas storage area $(G)$.

The plasma generator shows laminary stabilization. The power source has a descending characteristic (Fig.1.b). The idle operation voltage is $260 \mathrm{~V}_{\mathrm{dc}} \pm 5 \%$. It yields a current through the electric arc, which is continually adjustable between $70 \mathrm{~A}_{\mathrm{dc}} \pm 10 \%$ and $350 \mathrm{~A}_{\mathrm{dc}} \pm 5 \%$. The material advance system together with the material fixing-positioning system allows the uniform insertion of material in the plasma and the positioning of the electrode rod (pos. 3 in Fig.1.a). The advance velocity of the electrode rod can be continually adjusted between $0.20 \times 10^{-3} \mathrm{~m} / \mathrm{s} \pm 1 \%$ and $1.5 \times 10^{-3} \mathrm{~m} / \mathrm{s} \pm 1 \%$.

By means of device $\mathrm{P}$, the angle of incidence of the electrode rod and the plasma jet can be adjusted between $\pi / 6 \mathrm{rad}$ and $\pi / 2 \mathrm{rad}$ and the distance $\delta$ between $1.5 \times 10^{-3} \mathrm{~m} \pm 1 \%$ and $25 \times 10^{-3} \mathrm{~m} \pm 2 \%$. The plasma generator can function as plasma jet (closed $\mathrm{K}$ contact) or as transferred arc (open K contact).

The plasmagen gas storage area consists of argon tubes (150 bar). A pressure reductor (150 bar/1.5 bar) with flowmeter has been mounted on each plasmagen gas tube. The argon flow can be continually adjusted between $0.10 \times 10^{-3} \mathrm{~m}^{3} / \mathrm{s} \pm 5 \%$ and $60 \times 10^{-3} \mathrm{~m}^{3} / \mathrm{s} \pm 2 \%$.

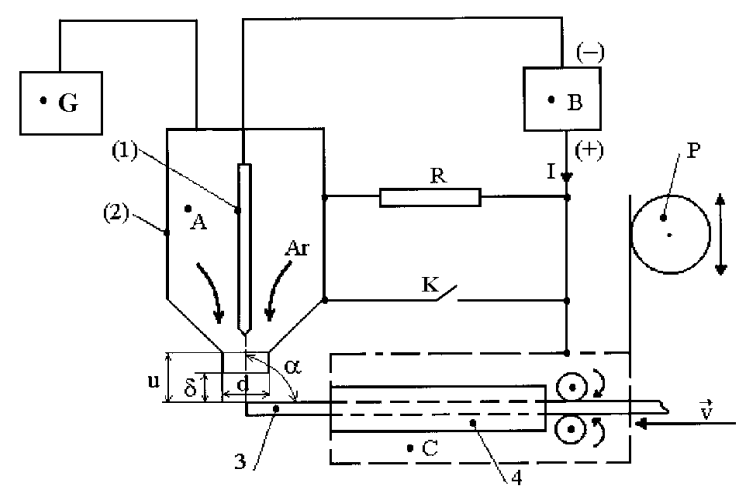

(a)

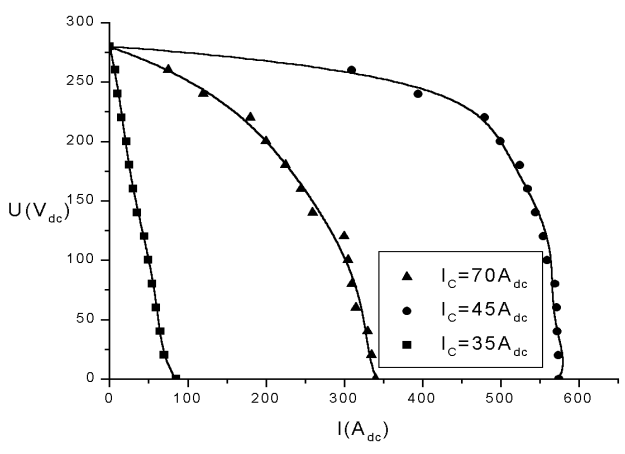

(b)

Fig.1. (a) Overall configuration of the installation utilized for iron micro-tube production in plasma: A-plasma generator; B-current source; C-material advance system; P-positioning-fixing system for material; 1-cathode; 2nozzle; 3-material (carbon steel rod); 4-contact nozzle cooled with water; d-nozzle diameter, $\delta$ =nozzle material distance; $\alpha$-attack (incidence) angle; v-material advance speed; I-current intensity; U-tension on arc; K-switch; Ar-argon admission; $\longleftrightarrow$-rod advance direction; $\downarrow$ rod up-down positioning.

(b) Static characteristics of the power source for various values of the command current $I_{c}$ of the magnetic amplifier. 


\section{Experimental result and discussion}

The installation in Fig.1.a is used for the production of cavitational microparticles in plasma. The material from which cavitational microparticles are obtained in plasma is a carbon steel rod.

The diameter $\mathrm{d}_{\mathrm{e}}$ of the rod is $3 \times 10^{-3} \mathrm{~m} \pm 10 \%$. The chemical composition of the steel (\% mass) is C: 0.19; Mn: 10.85; P: 0.045; S: 0.045; Si: 0.40; Fe: 88.47. The plasma generator has a nozzle of diameter $\mathrm{d}=2.0 \times 10^{-3} \mathrm{~m}$. The distance between the nozzle of the plasma generator and the rod is fixed at $\delta=6.0 \times 10^{-3} \mathrm{~m}$ and $\alpha=\pi / 2 \operatorname{rad}$ (Fig.1.a).

The intensity of the electric current through the plasma arc transferred onto the electrode rod is $\mathrm{I}=175 \mathrm{~A}_{\mathrm{dc}}$. The velocity $\mathrm{v}$ of the rod and the argon flow $\mathrm{D}$ are values which change during the experiment. At $\mathrm{v}=1.25 \times 10^{-3} \mathrm{~m} / \mathrm{s}$ and $\mathrm{D}=0.35 \times 10^{-3} \mathrm{~m}^{3} / \mathrm{s}$, parts of the rod melt. The melt, in continuous flow, is transported by the plasmagen gas. By solidification, a compact mass is obtained. By increasing the advance velocity of the rod to $\mathrm{v}=1.10 \times 10^{-3} \mathrm{~m} / \mathrm{s}$, iron microparticles and solidified melt are obtained (Fig.2.a).

We hold the advance velocity of the rod at the same value. But when we increase the argon flow to $1.00 \times 10^{-3} \mathrm{~m}^{3} / \mathrm{s}, 95 \%$ iron microparticles result (Fig.2.b). One can see through the optic microscope that some of microparticles have pores, as shown in Fig.2.c. Analysis of about 450 particles shows that $35 \%$ are pore microspheres. The mean microsphere has its diameter of $10 \mu \mathrm{m}$ and its wall thickness of $0.75 \mu \mathrm{m}$.

At $\mathrm{v}=1.25 \times 10^{-3} \mathrm{~m} / \mathrm{s}$ and $\mathrm{D}=0.65 \times 10^{-3} \mathrm{~m}^{3} / \mathrm{s}$, there result microparticles, microspheres and, respectively, about 15\% microparticles having a central nucleus (microsphere) out of which ligaments stick in the same plan. In Fig.3 one can see that the ligaments are empty. The particles displaying such shapes will be referred to by us as octopus-shaped microparticles. The mean sizes of the octopus-shaped microparticles are:

-for the nucleus (mean diameter: $12 \mu \mathrm{m}$ and wall thickness: $0.5 \mu \mathrm{m}$ ) and, -for the ligaments (length: $188 \mu \mathrm{m}$, equivalent diameter: $2 \mu \mathrm{m}$ and wall thickness: $0.35 \mu \mathrm{m}$ ).

At $v=1.15 \times 10^{-3} \mathrm{~m} / \mathrm{s}$ and $\mathrm{D}=0.75 \times 10^{-3} \mathrm{~m}^{3} / \mathrm{s}$, a movement of the melt is noticed in the plasma as continuous and parallel lines. Following solidification, fibres result as those in Fig.4.a. Seen on the optic microscope, they appear like microtubes of shapes and sizes as shown in Figs. 4b-4d. The mean microtube is characterized by: length: $100 \mu \mathrm{m}$; diameter: 3 $\mu \mathrm{m}$ and wall thickness: $0.25 \mu \mathrm{m}$.

The cavitational microparticles (Figs.2,3 and 4) have their surface covered with $\mathrm{Fe}_{3} \mathrm{O}_{4}$ (Fig.5). The presence of $\mathrm{Fe}_{3} \mathrm{O}_{4}$ is due to the oxigen traces in the technical argon. 


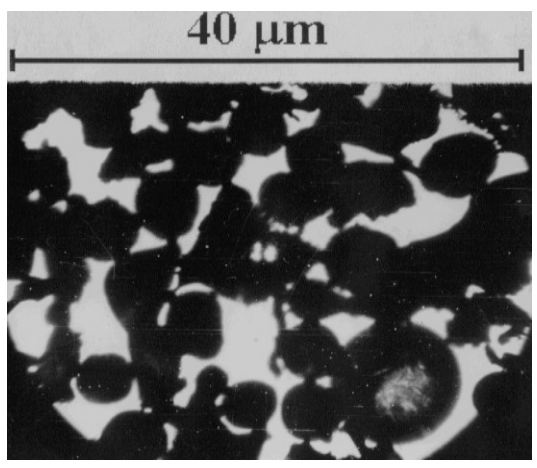

(a)

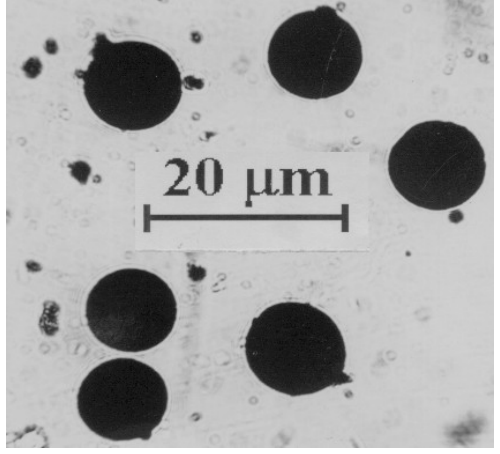

(b)

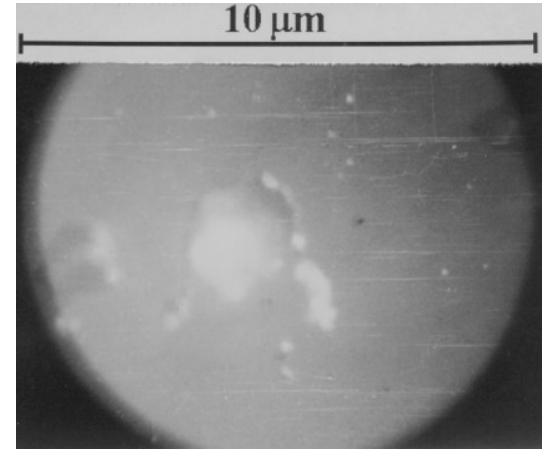

(c)

Fig.2. Shapes and sizes of the iron microparticles: (a) microparticles, microspheres and melted iron mass; (b) microparticles and microspheres; (c) pore microspheres.

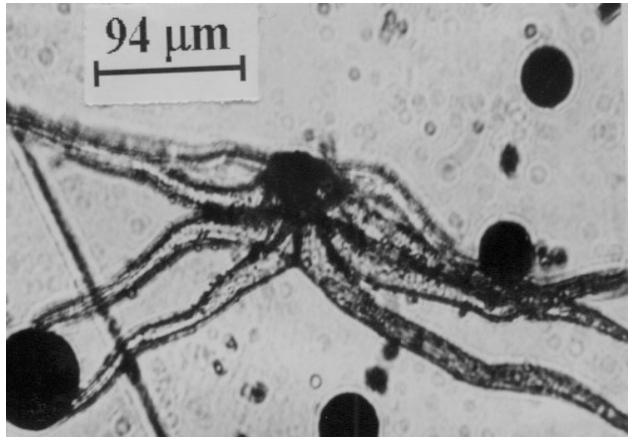

(a)

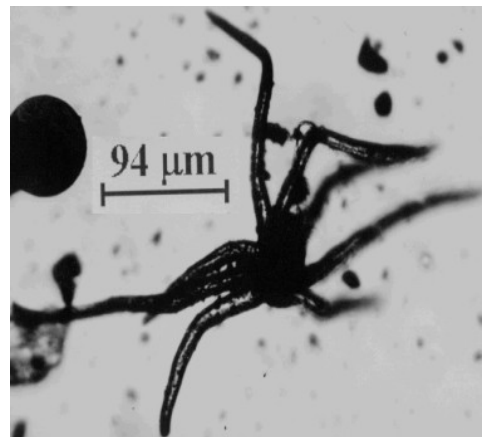

(b)

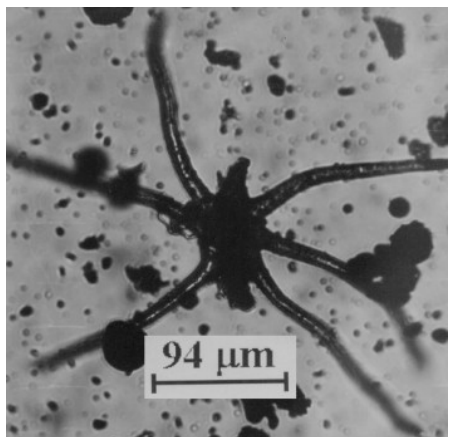

(c)

Fig.3. Octopus-shaped iron microparticles

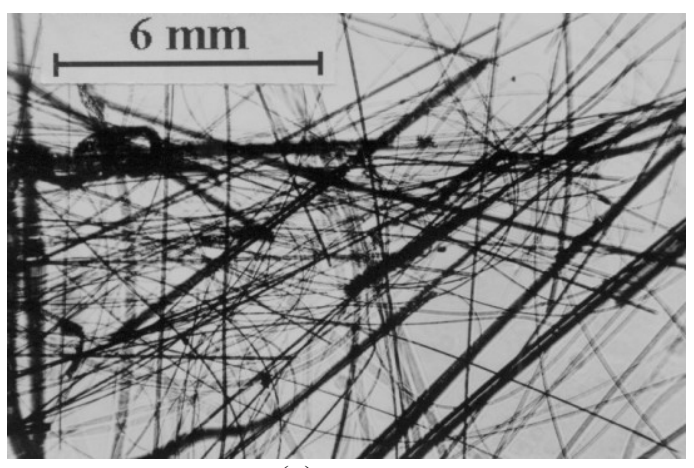

(a)

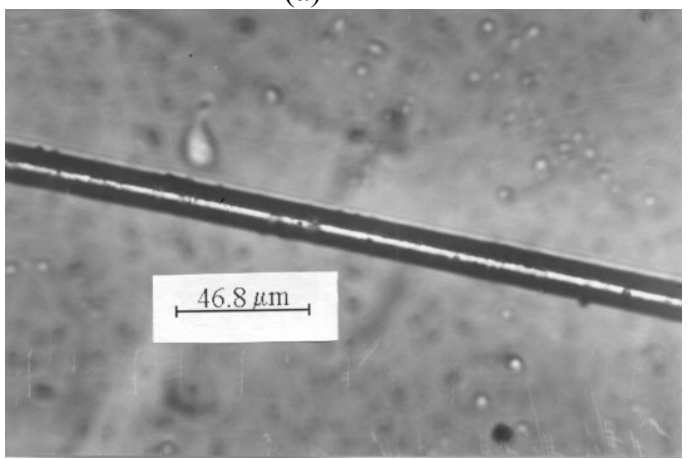

(c)

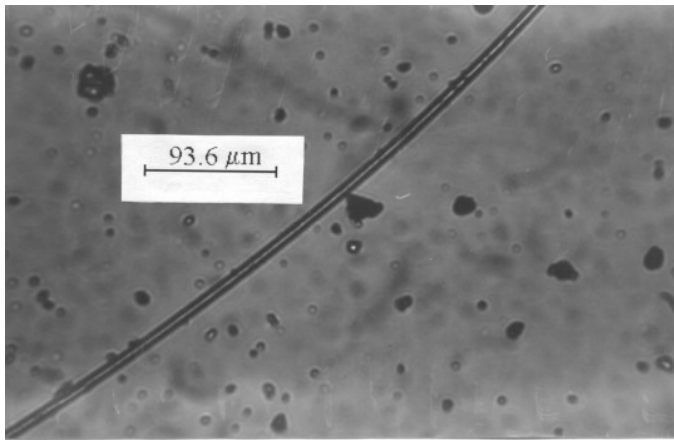

(b)

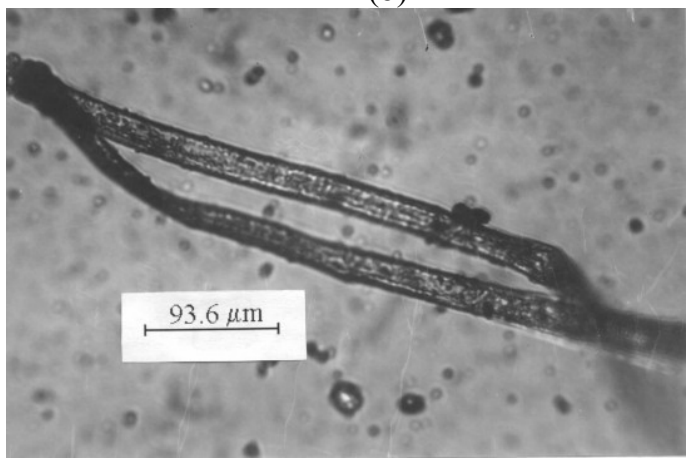

(d)

Fig.4. Iron fibres (a) and iron microtubes (b,c,d) 


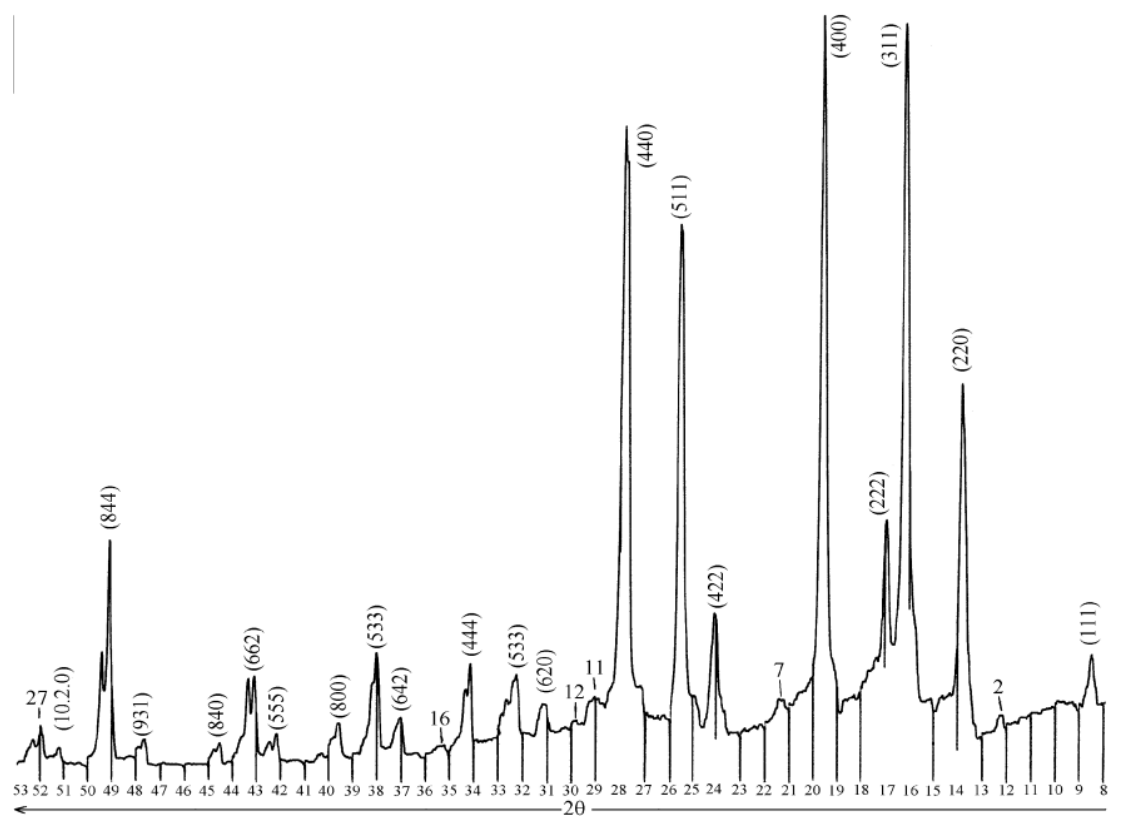

Fig.5. X-ray diffraction patterns of iron cavitational microparticles

450 cavitational microparticles are considered. The mean volume occupied by the iron layer is calculated. Further, the volume occupied by the liquid is determined and the iron concentration contained by a mean cavitational microparticle is calculated. The results obtained are those in Table 1.

Table 1. Volume concentration of iron in the cavitational microparticles

\begin{tabular}{|c|c|c|c|}
\hline $\begin{array}{c}\text { Type of } \\
\text { microparticle }\end{array}$ & Microsphere & Microtube & $\begin{array}{c}\text { Octopus-Shaped } \\
\text { microparticles }\end{array}$ \\
\hline $\begin{array}{c}\text { Volume } \\
\text { Concentration }(\%)\end{array}$ & $\sim 12$ & $\sim 35$ & $\sim 10$ \\
\hline
\end{tabular}

\section{Conclusions}

- The installation in Fig.1.a allows obtaining microparticles in general and cavitational microparticles in particular;

- By maintaining the discharge current at constant values, cavitational microparticles are obtained by modifying the argon flow and, respectively, the material advance velocity;

- The iron concentration of the microparticles can be controlled by using the plasma procedure (Table 1). 


\section{References}

[1] T. Nakamura. Magnetomedicine-characteristics of fine ferromagnetic particles. J. Appl. Phys. $\underline{42}$ (1971), 1320-1324;

[2] A. Senyei, K. Reich, C. Conezy, K. Widder. In vivo kinetics of magnetically targeted low-dose dexorubicin. J. Pharm. Science 70 (1991), 383-391;

[3] K. Widder, A. Senyei. Magnetic microspheres: a vehicle for selective targeting of drugs. J. Pharm. Therapy $\underline{20}$ (1983), 377-396;

[4] V.M. Chikov, A.A. Kuznetsov, W. Schütt. Analiticall cell magnetophoresis. In: Physical characterisation of bilogical cells. Verlag Gesundheit GmbH Berlin (1991), pp. 381-389;

[5] A.A. Kuznetsov, V.M. Chikov, A. M. Shapiro, S. Winoto-Morbach, W. Müller-Rucholtz. Single cell magnetophoresis and its diagnostic value. J.Magn.Magn. Mater. 122 (1993), 367370 ;

[6] A.A. Kuznetsov, A.R. Harutyunyan, E.K. Dobrinsky, V.I. Filippov, A.G. Malenkov, A.F.Vanin, O.A. Kuznetsov. Ferro-carbon particles: Preparation and Clinical Applications. In: Scientific and Clinical Applications of Magnetic Carriers. Ed. by Häfeli et al. Plenum Press. New-York, 1997, pp. 379-389;

[7] A.A. Kuznetsov, V.I. Filippov, O.A. Kuznetsov, V.G. Gerlivanov, E.K.Dobrinsky, S.I.Malashin. New ferro-carbon adsorbants for magnetically quided transport of anti-cancer drugs. J.Magn.Magn. Mater. 194 (1999), 22-30;

[8] U.O. Häfeli, G.J.Pauer. In vitro and vivo toxicity of magnetic microspheres. J.Magn.Magn. Mater. 194 (1999), 76-82;

[9] I. Bica. On the mechanisms of iron microspheres formation in argon plasma jet. J.Magn.Magn. Mater. 257 (2003), 119-125;

[10] I. Bica. Pore formation in iron microspheres by plasma procedure. Mater. Sci. Eng. $\underline{A}$ $\underline{303}$ (2005), 191-195;

[11] I. Bica. Formation of iron microtubes in plasma. J.Magn.Magn.Mater. 270,1-2 (2004), 7-14;

[12] I. Bica. Some mechanisms for the formation of octopus-shaped iron microparticles. J.Magn.Magn. Mater. 279, 2-3 (2004), 289-298; 